\title{
Occurrence of Rabl-Like Telomere Clustering in the Holocentric Chromosomes of the Peach Potato Aphid Myzus persicae (Hemiptera; Aphididae)
}

\author{
Mauro Mandrioli Sarah Bandinelli Gian Carlo Manicardi \\ Dipartimento di Scienze della Vita, Università di Modena e Reggio Emilia, Modena, Italy
}

\section{Key Words}

Aphids · Chromatin - $C_{0}$ t DNA · Holocentric chromosomes · Immunoprecipitation - LEM-2 $\cdot$ Myzus persicae $\cdot$ Rabl

configuration · Repeated DNA

\begin{abstract}
Several studies demonstrated that chromosome anchoring to nuclear structures is involved in the organization of the interphase nucleus. The Rabl configuration, a well-studied chromosome organization in the interphase nucleus, has been deeply studied in organisms with monocentric chromosomes but just slightly touched in species with holocentric chromosomes. In the present paper, by means of the isolation and chromosomal mapping of the $C_{0}$ t DNA fraction and chromatin immunoprecipitation with anti-LEM-2 antibodies, we evidenced the presence of few foci where telomeres and subtelomeric regions cluster in the aphid interphase nuclei, suggesting the occurrence of a Rabl-like chromosome configuration. The same experimental approaches also evidenced that most of the repetitive DNA of the $2 \mathrm{X}$ chromosomes is located at the periphery of the nucleus, whereas the ribosomal genes, located at 1 telomere of each $X$ chromosome, are present towards the inner portion of the nucleus, favoring their transcriptional activity.
\end{abstract}

(c) 2014 S. Karger AG, Basel

\section{KARGER}

(C) 2014 S. Karger AG, Base

1424-8581/14/1441-0068\$39.50/0

E-Mail karger@karger.com

www.karger.com/cgr
Interphase is an important phase of the eukaryotic cell cycle, since it is during this stage that the genetic information contained in chromosomes is transcribed [Dong and Jiang, 1998; Shaw et al., 2003; Schneider and Grosschedl, 2007]. In view of this important role, the relationship between structure and function of chromatin in the nucleus has been an area of speculation since the Rabl finding more than a century ago [Rabl, 1885].

In the interphase nucleus each chromosome occupies a well-defined territory, as assessed by chromosome painting of animal chromosomes and genomic in situ hybridization in plants [for a review, see Leitch, 2000]. In particular, a detailed examination of the chromosome organization in interphase nuclei has been performed in human cells, showing that in each chromosomal territory chromatin is folded differently in order to define domains that reflect different types and/or activities of chromatin [Leitch, 2000].

The right positioning of chromosomes is favored by their anchoring to nuclear structures (such as the nuclear envelope, the nuclear lamina, and the nucleolus) by means of centromeres and/or telomeres [Gilson et al., 1993; Ostashevsky, 2002]. These attachments are important not only from a cytological point of view but also since they are involved in the regulation of gene expression so that, as a general rule, the location of genes in

Mauro Mandrioli

Dipartimento di Scienze della Vita

Università di Modena e Reggio Emilia

Via Campi 213/D, IT-41125 Modena (Italy)

E-Mail mauro.mandrioli@unimo.it 
proximity to telomeres or centromeres favors their silencing [Cockell and Gasser, 1999; Gasser, 2001; Santos et al., 2002].

The relevance of these nuclear structures, which contribute to the functional regulation of the genome, is demonstrated by the laminopathies. Indeed, numerous pathologies have been recently studied with regard to mutations in protein constituents of the nuclear envelope/lamina [Spector, 2003]. In the X-linked EmeryDreifuss muscular dystrophy (X-EDMD) disease, for instance, mutations have been identified in the gene coding for emerin, a type II integral membrane protein localized in the inner nuclear envelope [Wilson, 2000]. In particular, it has been observed that a mutated emerin gene makes cells unable to properly sequester inactive chromatin at the nuclear periphery, thereby leading to an altered gene regulation [Wilson, 2000].

Due to their functional relevance in genome regulation, several nuclear membrane proteins are highly conserved, as reported for the LEM-2 protein, a transmembrane protein containing the LEM domain, that has homologs in a wide variety of organisms (including yeast, mouse, fly, human, and the worm Caenorhabditis elegans) and is expressed in every human, mouse and $C$. elegans cell where it has been localized in the inner nuclear membrane [Lee et al., 2000; Brachner et al., 2005; Ulbert et al., 2006; Grund et al., 2008]. In human and C. elegans, LEM-2 interacts with lamins in vitro and requires them for its localization to the nuclear membrane [Lee et al., 2000; Brachner et al., 2005; Ulbert et al., 2006; Grund et al., 2008].

The presence of chromosome anchoring is at the basis of some peculiar chromosomal configurations that have been described in the literature [Ostashevsky, 2002]. A well-studied example is the Rabl chromosome configuration where centromeres and telomeres serve as anchors, with centromeres forming a cluster at one side of the nuclear envelope while the telomeres are located at another side [Ostashevsky, 2002].

Even if telomeres and centromeres are frequently attached to nuclear structures, whether the Rabl configuration is a conserved feature of the eukaryotic cells is still an open question. In fact, despite its occurrence in dividing tissues of several plant, yeast, and mammalian species [Comings, 1980; Sperling and Luedeke, 1981; Cremer et al., 1982a, b; Funabiki et al., 1993; Dong and Jiang, 1998; Jin et al., 1998; Schubert and Shaw, 2011], the Rabl model seems not to be universal. Chung et al. [1990], for instance, used FISH to analyze the positions of telomeres in Trypanosoma brucei and showed that telomeres appeared scattered across the nucleus, suggesting that the Rabl con-

Rabl Telomere Clustering in Aphids figuration is absent. Similarly, Zea mays, Sorghum bicolor, and Arabidopsis thaliana chromosomes do not exhibit the Rabl configuration [Rawlins and Shaw, 1990; Dong and Jiang, 1998; Schubert and Shaw, 2011].

Altogether, it seems that the occurrence of the Rabl configuration is not a consequence of the genome organization; neither is it related to the genome size, because some small genomes (such as yeasts) show it whereas the small Trypanosoma genome does not [Schubert and Shaw, 2011]. Similarly, the presence of the Rabl configuration is also not related to the genome size in mammals, suggesting that other features may drive the presence of this peculiar chromosome organization [Schubert and Shaw, 2011].

Interestingly, most data about the presence of the Rabl configuration have been obtained in organisms with monocentric chromosomes whereas species with holocentric chromosomes have been just slightly investigated. Holocentric chromosomes are unusual chromosomes, since they possess a diffuse centromeric activity so that they bind to microtubules along their entire length and move broadside to the pole from the metaphase plate [Hughes-Schrader and Schrader, 1961; White, 1973; Wrensch et al., 1994]. These chromosomes, also termed holokinetic because chromatids move apart in parallel and do not form the classical V-shaped figures typical of monocentric chromosomes [Wrensch et al., 1994], have been observed in different metazoa, including some insects (such as moths and butterflies, aphids, coccids, earwigs, and triatomines), nematodes, and arachnids [Wrensch et al., 1994].

At this regard, the Rabl configuration has been studied in the holocentric chromosomes of the plant Cuscuta approximata where the analysis of the mitotic and meiotic chromosome behavior did not show any evidence of a chromosomal Rabl orientation [Guerra and García, 2004]. Similarly, Schweizer and Loidl [1987] suggested that the dispersed distribution of heterochromatin observed in holocentric chromosomes (in place of its equilocal distribution typically reported in monocentric chromosomes) should make organisms with holocentric chromosomes not dependent on the Rabl configuration, also considering that the centromere-attached Rabl configuration is impossible for holocentric chromosomes. However, the discontinuous distribution of holocentrism in protista, animals, and plants suggested that holocentric chromosomes have arisen multiple times during evolution [Mandrioli and Manicardi, 2012] so that the absence of the Rabl configuration in plants could not be indicative of its absence in all species possessing 
holocentric chromosomes. Furthermore, the use of a quantitative model to study large-scale chromatin organization in different organisms suggested that a Rabl-like configuration could be possible, even if limited to telomeres, in the worm Caenorhabditis elegans that possesses holocentric chromosomes [Ostashevsky, 2002].

In view of the presence of a low chromosome number and taking into account that aphids could be particularly useful for cytogenetic studies since mitotic chromosomes can be easily obtained from their embryonic tissues, aphids can be intriguing experimental models for studying the chromosomal configuration in the nucleus of organisms possessing holocentric chromosomes. In view of recent papers showing that the chromosomal mapping of the repeated $\mathrm{C}_{0} \mathrm{t}$ DNA fraction represents a powerful, inexpensive, and not time-consuming tool to understand the genomic organization of highly repetitive sequences [Cabral-de-Mello et al., 2011], we isolated and mapped the $\mathrm{C}_{0} \mathrm{t}$ DNA fraction in 3 clones of the aphid M. persicae. This approach allowed us to analyze the distribution of repetitive DNAs which have been utilized as markers in order to highlight chromosome organization. Moreover, we used 2 satellite DNAs, the Hind200 satellite and the subtelomeric repeat that label the intercalary heterochromatic bands of the X chromosomes [Mandrioli et al., 1999a] and the subtelomeric regions of each autosome and a single subtelomeric region on both the X chromosomes, respectively [Spence et al., 1998], in order to evaluate their distribution in the aphid interphase nuclei. Lastly, we analysed the distribution of these 2 repetitive DNAs by chromatin immunoprecipitation (ChIP) experiments using anti-LEM-2 antibodies, assessing that most of the repetitive DNA of the X chromosomes in M. persicae is located at the nucleus periphery, whereas the ribosomal genes (located at 1 telomere of the $2 \mathrm{X}$ chromosomes) are present toward the inner portion of the nucleus, favoring their transcriptional activity.

\section{Material and Methods}

Specimens of $M$. persicae were obtained from 3 aphid strains (labeled as lav1, lav2, and lav3) collected in Reggio Emilia (Italy) on Lavanda sp. plants. Each population was established as a clone from a single female aphid originally collected from the field and thereafter maintained as a colony of parthenogenetic females on pea (Pisum sativum) plants at $19^{\circ} \mathrm{C}$ with a light-dark regime of $16 \mathrm{~h}$ light and $8 \mathrm{~h}$ darkness.

Chromosome preparations were carried out from parthenogenetic females by spreading embryo cells. In particular, adult females were dissected in a $0.8 \%$ hypotonic solution of sodium citrate saline solution, and embryos were kept in the same solution for $30 \mathrm{~min}$. Afterwards, embryos were transferred to minitubes and centrifuged at 3,000 $\mathrm{g}$ for $3 \mathrm{~min}$. Methanol-acetic acid 3:1 was added to the pellet which was made to flow up and down for $1 \mathrm{~min}$ through a needle of a 1-ml hypodermic syringe to obtain disgregation of the material followed by a further centrifugation at $3,000 \mathrm{~g}$ for $3 \mathrm{~min}$. This step was repeated with fresh fixative. Finally, the pellet was resuspended in new fixative, and $20 \mu$ l of cellular suspension were dropped onto clean slides.

DNA extraction has been performed following the phenolchloroform protocol described in Mandrioli et al. [1999a].

The isolation of the DNA fraction enriched for highly repetitive DNA sequences ( $\mathrm{C}_{0} \mathrm{t} \mathrm{DNA}$ ) was done using the protocol described by Zwick et al. [1997], including modifications later published [Ferreira and Martins, 2008]. Briefly, DNA samples (50 $\mu$ l of a 500$\mathrm{ng} / \mathrm{ml}$ solution of genomic DNA in $0.3 \mathrm{M} \mathrm{NaCl}$ ) were autoclaved for $3 \mathrm{~min}$ at $120^{\circ} \mathrm{C}$, and the fragmented DNA (consisting of fragments ranging in size from $100-800 \mathrm{bp}$ ) was separated by $1 \%$ agarose gel electrophoresis. DNA samples were successively denatured at $95^{\circ} \mathrm{C}$ for $10 \mathrm{~min}$, placed on ice for $10 \mathrm{~s}$, and transferred into a $65^{\circ} \mathrm{C}$ water bath for reannealing for $3 \mathrm{~min}$. Samples were subsequently incubated at $37^{\circ} \mathrm{C}$ for 8 min with $1 \mathrm{U}$ of S1 nuclease to permit the digestion of single-stranded DNA. The samples were immediately frozen in liquid nitrogen, and the DNA was extracted using the previously reported phenol-chloroform procedure. The reported $\mathrm{C}_{0} \mathrm{t}$ protocol has been defined in order to allow the reannealing of only the highly repetitive AT-rich DNA, avoiding the presence of other repetitive DNA, such as ribosomal genes, in the $\mathrm{C}_{0} \mathrm{t}$ DNA.

The $\mathrm{C}_{0} \mathrm{t}$ DNA fraction was labeled with the random priming DIG labeling kit (Roche Diagnostics, Mannheim, Germany) and used as a probe in FISH experiments, performed as described by Mandrioli et al. [2011].

Staining with $100 \mathrm{ng} / \mathrm{ml}$ propidium iodide in phosphate buffer has been carried out for $15 \mathrm{~min}$ at room temperature in order to evaluate the chromosome number. For each different karyotype observed, measurements of chromosome length were performed on 80 metaphase plates using the software MicroMeasure, available at the Biology Department of Colorado State University website (http://rydberg.biology.colostate.edu/MicroMeasure).

Propidium-stained and FISH slides were observed using a Zeiss Axioplan epifluorescence microscope. Photographs of the fluorescent images were taken using a CCD camera (Spot, Digital Instrument, Madison, Wis., USA) and the Spot software supplied with the camera and processed using Adobe Photoshop (Adobe Systems, Mountain View, Calif., USA).

ChIP experiments with LEM-2 antibodies (Novus Biologicals, Littleton, Colo., USA) have been performed using mixed-stage aphid embryos as described by Ercan et al. [2007], including the modifications reported by Ikegami et al. [2010] related to the use of $10 \mu \mathrm{g}$ polyclonal anti-LEM-2 antibodies immobilized onto Protein A-conjugated sepharose beads which were subsequently incubated at $4^{\circ} \mathrm{C}$ for over $12 \mathrm{~h}$ with the chromatin extract.

Amplification of the subtelomeric repeat has been performed using the specific oligonucleotide primers MpR-F (5'-TCAAAGTTCTCGTTCTCC- $\left.3^{\prime}\right)$ and MpR-R (5'-GTTTTAACAGAGTGCTGG-3'), designed using the subtelomeric repeat sequence available in the literature [Spence et al., 1998]. The reaction conditions were $94^{\circ} \mathrm{C}$ for $90 \mathrm{~s}$ (denaturation), a total of 25 cycles of $94^{\circ} \mathrm{C}$ for $30 \mathrm{~s}, 51^{\circ} \mathrm{C}$ for $30 \mathrm{~s}$ (annealing) and $72^{\circ} \mathrm{C}$ for $30 \mathrm{~s}$ (extension), and a final extension step at $72^{\circ} \mathrm{C}$ for $7 \mathrm{~min}$. 
Amplification of the Hind200 satellite DNA has been performed using the specific oligonucleotide primers Hind200-F $\left(5^{\prime}\right.$-ACGTCCTCTAAAGAACGGTGT- $\left.3^{\prime}\right)$ and Hind200-R ( $5^{\prime}$-GCTTTCTTTTGGACTAGAGTAATATGG-3'), designed using the Hind 200 sequence available in GenBank (AF161255). The reaction conditions were $94^{\circ} \mathrm{C}$ for $90 \mathrm{~s}$, a total of 25 cycles of $94^{\circ} \mathrm{C}$ for $30 \mathrm{~s}, 51^{\circ} \mathrm{C}$ for $30 \mathrm{~s}$, and $72^{\circ} \mathrm{C}$ for $30 \mathrm{~s}$, and a final extension step at $72^{\circ} \mathrm{C}$ for $7 \mathrm{~min}$.

The 28S rDNA genes have been amplified using the primers F ( $5^{\prime}$-AACAAACAACCGATACGTTCCG- $\left.3^{\prime}\right)$ and R ( $5^{\prime}$-CTCTGTCCGTTTACAACCGAGC- $3^{\prime}$ ), designed using to the insect $28 \mathrm{~S}$ rDNA sequences available in GenBank. Amplification was performed using a Hybaid thermal cycler at an annealing temperature of $60^{\circ} \mathrm{C}$ for $1 \mathrm{~min}$ with an extension time of $1 \mathrm{~min}$ at $72^{\circ} \mathrm{C}$.

For each primer pair, the amplification mix contained $80 \mathrm{ng}$ LEM-2 immuno-precipitated DNA as template, $1 \mu \mathrm{M}$ of each primer, $200 \mu \mathrm{M}$ dNTPs, and $2 \mathrm{U}$ of DyNAZyme II polymerase (Finnzymes Oy, Vantaa, Finland). The results of the PCR amplification have been evaluated by $1.2 \%$ agarose gel electrophoresis.

\section{Results}

The isolation and chromosomal mapping of the $M$. persicae AT-rich $\mathrm{C}_{0} \mathrm{t}$ fraction revealed that highly repetitive DNA sequences were located on chromosome ends at prometaphase (figs. 1a, 2d-f) and clustered at interphase (fig. 1b). In particular, most of the AT-rich $\mathrm{C}_{0}$ t fraction labeled the nucleus periphery, whereas no signals occurred near the nucleolus, evidenced by simultaneous FISH with the GC-rich $28 \mathrm{~S}$ rDNA probe (fig. 1b).

By combining the $\mathrm{C}_{0} \mathrm{t}$ probe localization and the measurement of the chromosomal length, it has been possible to analyze the spatial arrangement of chromosomes during prometaphase (fig. 1a, c), revealing that the terminal portions of different non-homologous chromosomes were tightly associated in the observed foci.

The karyotypes of the clones lav1, lav2, and lav3 have been analysed by staining with propidium iodide only (fig. $2 \mathrm{a}-\mathrm{c}$ ) and after hybridization with the $\mathrm{C}_{0} \mathrm{t}$ probe (fig. 2d-f). Information obtained after FISH with the $\mathrm{C}_{0} \mathrm{t}$ fraction combined with chromosome measurements demonstrated that the clone lav1 possessed a standard karyotype consisting of 12 chromosomes, including 5 pairs of autosomes with both the telomeres labeled and 2 $\mathrm{X}$ chromosomes that can be easily identified since they are the longest in the complement and unique with a single labeled telomere and fluorescent intercalary bands (fig. 2d). The metaphase plates observed in clone lav2 consisted of 13 chromosomes with a fission involving a single autosome 1 (fig. 2e), whereas the lav3 clone presented 14 chromosomes due to fissions involving autosomes 1 and 4 (fig. $2 \mathrm{f}$ ).

Rabl Telomere Clustering in Aphids
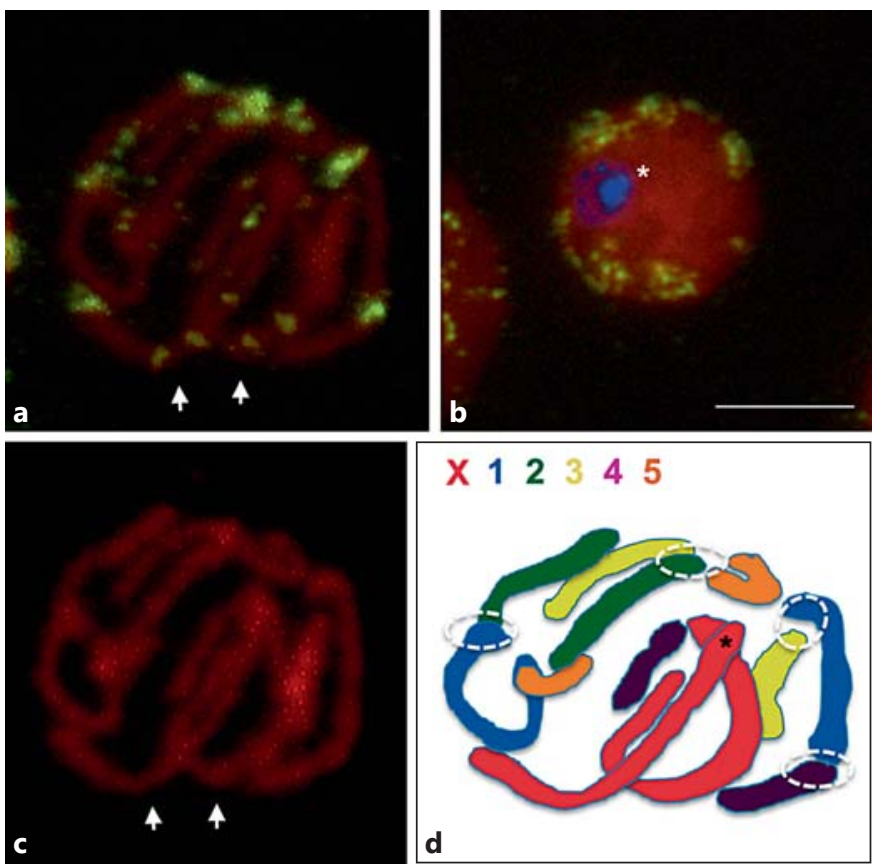

Fig. 1. In situ hybridization of the $\mathrm{C}_{0} \mathrm{t} \mathrm{DNA}$ fraction (green) on the M. persicae prometaphase chromosomes (a), counterstained with propidium iodide staining (c), has been combined to the micromeasure of the chromosomal length in order to map the position of each chromosome in the aphid interphase nucleus (d). At the same time, the $\mathrm{C}_{0} \mathrm{t}$ DNA fraction (green) has been hybridized on the $M$. persicae nuclei (b), together with a $28 \mathrm{~S}$ rDNA probe (blue), clearly evidencing the distribution of repetitive DNA at the nuclear periphery and not in a perinucleolar position. Asterisks corresponds to the nucleolus (in b) and to the NORs (in d). Arrows indicate the $\mathrm{X}$ chromosomes. Dotted circles in $\mathbf{d}$ indicate areas involved in the telomere clustering. Scale bar $=10 \mu \mathrm{m}$.

PCR amplification of the DNA samples obtained after ChIP with anti-LEM-2 antibodies evidenced that both the Hind200 satellite DNA (fig. 3a) and the subtelomeric DNA repeat (fig. 3b) were present in this fraction, whereas the $28 \mathrm{~S}$ rDNA genes were absent (fig. 3c), suggesting that the 2 satellite DNAs were LEM-2-associated at the nuclear membrane whereas the rDNA genes were within the inner portion of $M$. persicae nuclei. ChIP results are in agreement with cytogenetic data regarding the localization of the Hind200 satellite in the M. persicae nuclei (fig. $3 \mathrm{~d}$ ), suggesting that most of the repetitive DNA of the $2 \mathrm{X}$ chromosomes is associated with LEM-2 at the periphery of the nucleus (fig. 3e), whereas NOR regions are located in inner portions of the nucleus where they form the nucleolus. 

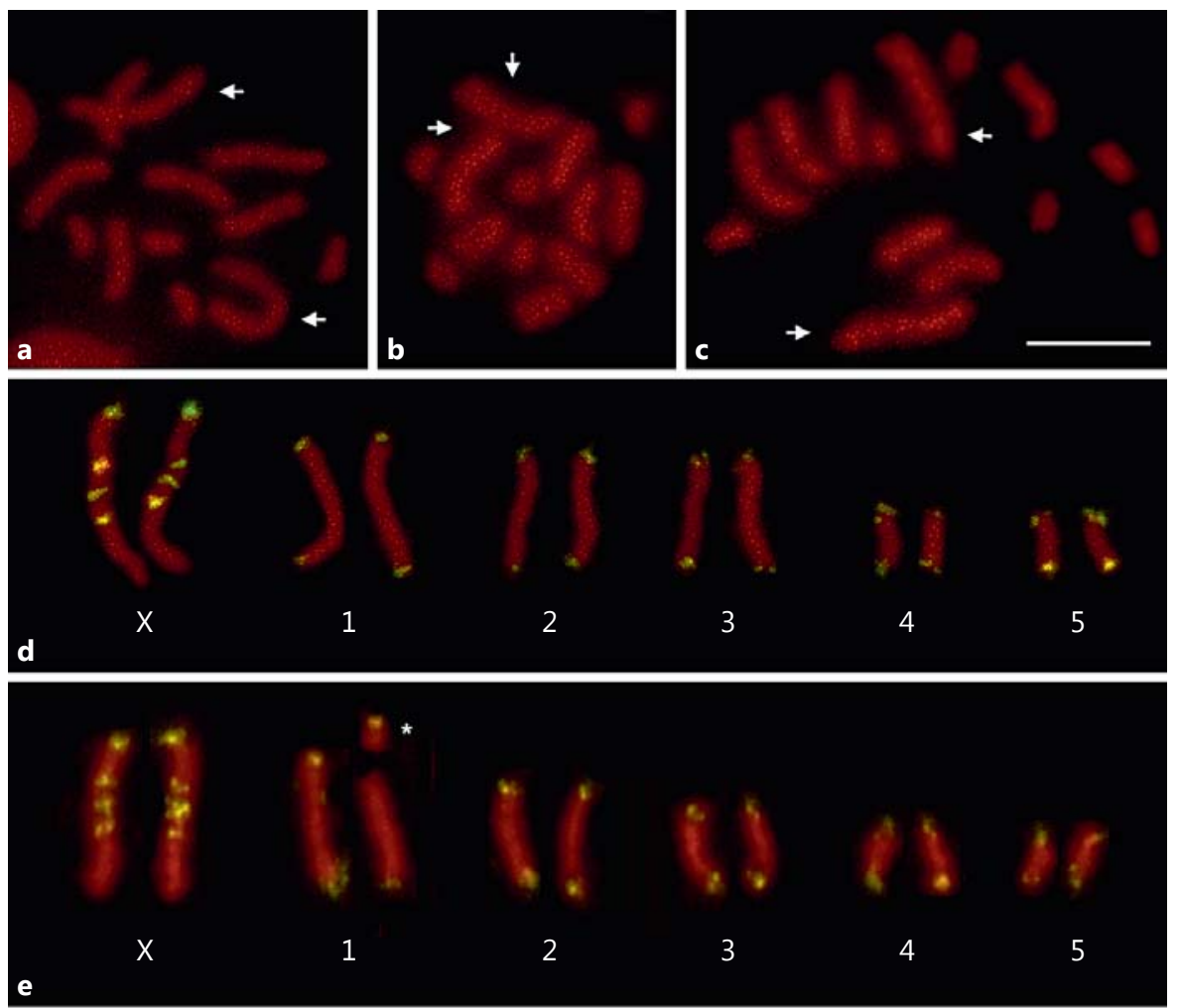

Fig. 2. Propidium iodide staining $(\mathbf{a}-\mathbf{c})$ and in situ hybridization of the $\mathrm{C}_{0} \mathrm{t}$ DNA fraction on chromosomes in clones lav1 $(\mathbf{a}, \mathbf{d})$, lav2 (b,e), and lav3 (c, f) allowed the reconstruction of the karyotype in each clone. Arrows indicated the X chromosomes. Asterisks in $\mathbf{e}$ and $\mathbf{f}$ indicate chromosome fissions. Scale bar $=10 \mu \mathrm{m}$.

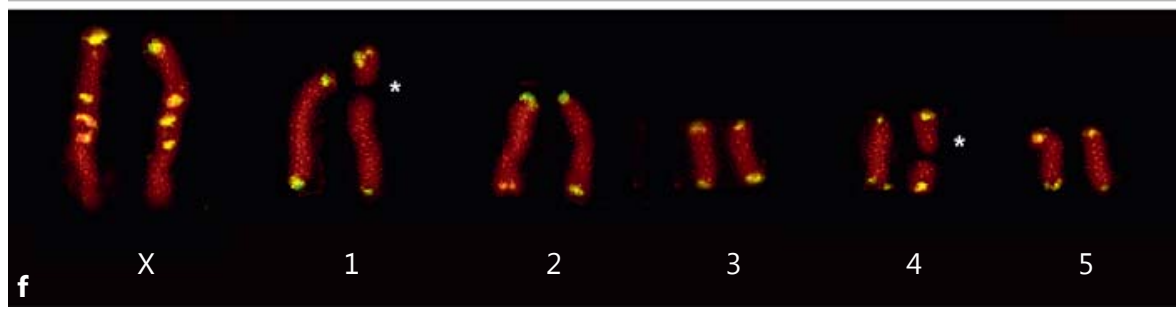

\section{Discussion}

A detailed understanding of the distribution and organization of chromatin in the nucleus is an important goal for current biosciences, since the nuclear architecture is essential for regulating several events including gene expression and chromosome pairing and recombination [Spector, 2003]. Interestingly, the architecture of the interphase nucleus follows similar rules in distantly related species so that, for instance, the nuclear envelope-associated chromatin possesses the same characteristics, such as high levels of histone H3K9 dimethylation and H3K27 trimethylation, low gene density and low gene expression [Pickersgill et al., 2006; Guelen et al., 2008; Peric-Hupkes et al., 2010], in human, mouse, and fly.

At present, several data are available about the organization of the interphase nucleus and the role of chromo- some anchoring at nuclear structures to obtain the right positioning of each chromosomes in the nucleus of plant and animal species with monocentric chromosomes [Leitch, 2000; Ostashevsky, 2002]. In contrast, few studies have been focused on these aspects in organisms possessing holocentric chromosomes [Guerra and García, 2004]. Therefore, isolation and chromosomal mapping of the $\mathrm{C}_{0}$ t fraction and ChIP with anti-LEM-2 antibodies have been applied in this work in order to understand the structure of the $M$. persicae interphase nucleus. The $\mathrm{C}_{0} \mathrm{t}$ DNA hybridization allowed us to simultaneously map the distribution of all the AT-rich highly repeated DNA sequences favoring the generation of information about the position of specific chromosomes in the nucleus. We used a short reannealing time for the $\mathrm{C}_{0} \mathrm{t}$ fraction in order to avoid the hybridization of GC-rich DNA sequences, such as ribosomal genes, thus allowing a clear-cut distinction 


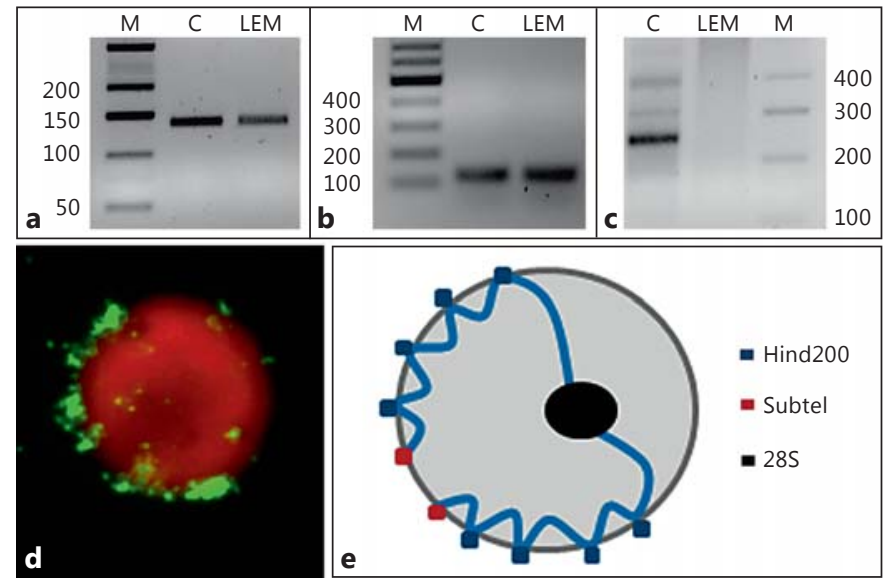

Fig. 3. PCR of Hind200 (a), the subtelomeric repeat (b), and $28 \mathrm{~S}$ rDNA (c) in the samples of chromatin immunoprecipitated with anti-LEM-2 antibodies (LEM) and in control DNA samples (C). Combining the in situ hybridization results with Hind200 (d) and those obtained from ChIP (a-c), the $2 \mathrm{X}$ chromosomes are present at the nuclear periphery with several LEM-2 domains attached to the nuclear lamina, as schematized in e. $\mathrm{M}=$ Molecular weight marker.

between the $2 \mathrm{X}$ telomeres, one being AT-rich (labeled after $\mathrm{C}_{0} \mathrm{t}$ DNA hybridization) and the other consisting of GC-rich rDNA genes [Mandrioli et al., 1999a].

At the chromosome level, $\mathrm{C}_{0} \mathrm{t}$ hybridization signals mainly correspond to the interstitial heterochromatic bands of the $M$. persicae $\mathrm{X}$ chromosomes [Mandrioli et al., 1999a] and to the heterochromatic subtelomeric regions of autosomes [Spence et al., 1998]. In the aphid interphase nucleus, FISH with the $M$. persicae $\mathrm{C}_{0} \mathrm{t}$ probe revealed that highly repeated DNA sequences are clustered into few foci, generally located near the nuclear periphery. Similar results have been observed in the initial meiotic cells and in the interphase nuclei of other species, and they mostly corresponded to clustered telomeres or telomere-associated repeated DNA sequences [Guelen et al., 2008].

Heterochromatin is presumed to be largely inactive, and it is often found either attached to or associated with the nuclear envelope as well as at internal locations in the nucleus [Leitch, 2000]. Cavalier-Smith [1978] postulated that heterochromatin may play a structural role, facilitating chromosome organization at interphase via nuclear envelope interactions. According to our data, despite the different distribution in respect to monocentric chromosomes, heterochromatin may play a similar role also in organisms possessing holocentric chromosomes.

Rabl Telomere Clustering in Aphids
The clustering of telomeric regions has been frequently observed in the literature, also as a part of the wellstudied Rabl configuration [Ostashevsky, 2002]. Organisms possessing holocentric chromosomes (with a diffuse centromere) cannot adopt a sensu stricto Rabl configuration since centromere clustering is not possible so that, as suggested by Schweizer and Loidl [1987], they may not dependent on the Rabl configuration. However, the study of chromatin organization at a large scale suggested that a telomere clustering could constitute a Rabl-like configuration involved in the nucleus organization in the holocentric chromosomes of C. elegans [Ostashevsky, 2002]. Our data as a whole suggested an anchored positioning to the nuclear lamina of $M$. persicae chromosomes by means of both telomeres for autosomes and a single telomere for the $2 \mathrm{X}$ chromosomes.

Interestingly, LEM-2 proteins have been used to better understand the position of the holocentric chromosomes in the C. elegans interphase nucleus, showing that the distal regions of autosomes are associated with the nuclear membrane through LEM-2 and are transcriptionally inactive, whereas the central regions are not connected with the membrane and are actively transcribed [Ikegami et al., 2010]. Similarly, genome-wide chromatin immunoprecipitation-on-chip analyses indicated that Src1, an inner nuclear membrane protein homologous to the vertebrate LEM-2, is highly associated with telomeres and subtelomeric regions of yeast chromosomes [Grund et al., 2008].

ChIP experiments with LEM-2 antibodies showed that both $M$. persicae satellite DNAs (Hind200 and the subtelomeric DNA repeat) are present in the LEM-2 immuno-precipitated genome fraction, whereas $28 \mathrm{~S}$ rDNA genes have not been amplified by PCR using the LEM-2 immunoprecipitated DNA as a template. Taking into account that Hind 200 has been reported as uniquely present on the X chromosomes [Mandrioli et al., 1999a], ChIP experiments support the results with the $\mathrm{C}_{0} \mathrm{t} \mathrm{DNA}$ in situ hybridization, suggesting a preferential localization of a portion of the $2 \mathrm{X}$ chromosomes at the nucleus periphery. However, the absence of the $28 \mathrm{~S}$ rDNA genes in the LEM2 immunoprecipitated fraction suggested that the NORbearing portion of the aphid X chromosomes is not at the periphery but is located inside the nucleus in order to form the nucleolus where the rDNA genes have to be expressed.

LEM-2 ChIP data are also interesting in view of esterase-based pesticide resistance, well-studied in M. persicae. Indeed, it has been observed that the autosomic A1A3 reciprocal translocation enhances the expression level 
of the $\mathrm{E} 4$ esterase genes so that aphids with this rearrangement produce a greater amount of the enzyme, thereby becoming resistant to a range of insecticides, i.e. organophosphates, carbamates, and pyrethroids [Blackman et al., 1978; Foster et al., 2007; Loxdale, 2009]. This effect is very interesting, considering that the $\mathrm{E} 4$ array is generally located near the subtelomeric region of the M. persicae autosome 3 which contains the tandem repetition of the subtelomeric satellite DNA [Blackman et al., 1978], and as a consequence of the translocation on autosome 1 , the esterase genes are distant from chromosomal regions associated with the LEM-2 protein. Considering that chromosomal associations with the nuclear membrane influence the epigenomic characteristics of a DNA trait [Reddy et al., 2008], the reposition of the esterase genes far from lamina-interacting regions could increase their expression level.

Previous analyses reported a clear-cut structural difference between the 2 telomeres of the X chromosome due to the absence of telomere-associated repeated sequences, such as satellite DNAs and TRAS retrotransposable elements, at the NOR telomeres [Spence et al., 1998; Monti et al., 2013]. This structural difference has been previously related to the need of favoring rDNA genes pairing which is involved in the reduction of the number of X chromosomes at the basis of the male determination in aphids [Mandrioli et al., 1999b]. LEM-2 data suggest that the observed structural difference could be also related to the spatial organization of the $\mathrm{X}$ chromosomes in the interphase nucleus. The clear-cut structural difference between the 2 telomeres could indeed permit their different positioning in the nucleus related to their different transcriptional activity.
According to literature data [Cremer et al., 2001], large chromosomes were frequently located toward the nuclear periphery, whereas small chromosomes were located toward the center of the nuclear projection. Interestingly, the same data suggested that chromosomes at the nuclear periphery were generally gene-poor so that also small chromosomes can be arranged at the periphery if containing few genes [Cremer et al., 2001]. On the basis of this assumption, our data suggest that aphid X chromosomes could be poor of genes despite their large dimension that makes them the largest chromosomes in the aphid complement. This hypothesis is supported not only by the large portion of the $\mathrm{X}$ chromosomes that appears to be heterochromatic [Mandrioli, 1999b] but also by estimations performed in the pea aphid Acyrthosiphon pisum suggesting that less than $12 \%$ of the annotated aphid genes are X-linked and that autosomes have a greater gene density than the $\mathrm{X}$ chromosome [Bickel et al., 2013].

According to previous data on the karyotype [Monti et al., 2012a, b], M. persicae chromosomes are frequently involved in rearrangements at their terminal portions. Therefore, it could be interesting to verify if the presence of telomere clustering could prefer the illegitimate endjoining of non-homologous chromosomes favored by the presence of several compounds with clastogenic effects (such as nicotine) in the aphid diet.

\section{Acknowledgments}

This work was supported by the grant 'Experimental Approach to the Study of Evolution' from the Department of Animal Biology of the University of Modena and Reggio Emilia to M.M.

\section{References}

Bickel RD, Dunham JP, Brisson JA: Widespread selection across coding and noncoding DNA in the pea aphid genome. G3 (Bethesda) 3: 993-1001 (2013).

Blackman RL, Takada H, Kawakami K: Chromosomal rearrangement involved in insecticide resistance of Myzus persicae. Nature 271:450 452 (1978).

Brachner A, Reipert S, Foisner R, Gotzmann J: LEM2 is a novel MAN1-related inner nuclear membrane protein associated with A-type lamins. J Cell Sci 118:5797-5810 (2005).

-Cabral-de-Mello D, de Moura Rde C, de Souza Melo A, Martins C: Evolutionary dynamics of heterochromatin in the genome of Dichotomius beetles based on chromosomal analysis. Genetica 139:315-325 (2011).
Cavalier-Smith T: Nuclear volume control by nucleoskeletal DNA, selection for cell volume and cell growth, and the solution of the DNA C-value paradox. J Cell Sci 34:247-278 (1978).

Chung HM, Shea C, Fields S, Taub RN, Van der Ploeg LH, Tse TB: Architectural organization in the interphase nucleus of the protozoan Trypanosoma brucei: location of telomeres and mini-chromosomes. EMBO J 9:26112619 (1990).

Cockell M, Gasser SM: Nuclear compartments and gene regulation. Curr Opin Genet Dev 9: 199-205 (1999).

Comings DE: Arrangement of chromatin in the nucleus. Hum Genet 53:131-143 (1980).

\footnotetext{
Cremer M, von Hase J, Volm T, Brero A, Kreth G, et al: Non-random radial higher-order chromatin arrangements in nuclei of diploid human cells. Chromosome Res 9:541-567 (2001).

-Cremer T, Cremer C, Baumann H, Luedtke EK, Sperling K, et al: Rabl's model of interphase chromosome arrangement tested in Chinese hamster cells by premature chromatin condensation and laser UV microbeam analysis. Hum Genet 60:46-56 (1982a).

-Cremer T, Cremer C, Schneider T, Baumann H, Hens L, Kirsch-Volders M: Analysis of chromosome positions in the interphase nucleus of Chinese hamster cells by laser-UV-microirradiation experiments. Hum Genet 62:201209 (1982b).
} 
Dong F, Jiang J: Non-Rabl patterns of centromere and telomere distribution in the interphase nuclei of plant cells. Chromosome Res 6:551558 (1998).

Ercan S, Giresi PG, Whittle CM, Zhang X, Green $\mathrm{RD}$, Lieb JD: X chromosome repression by localization of the C. elegans dosage compensation machinery to sites of transcription initiation. Nat Genet 39:403-408 (2007).

-Ferreira IA, Martins C: Physical chromosome mapping of repetitive DNA sequences in Nile tilapia Oreochromis niloticus: evidences for a differential distribution of repetitive elements in the sex chromosomes. Micron 39:411-418 (2008).

-Foster SP, Devine G, Devonshire AL: Insecticide resistance, in Van Emden HF, Harrington R (eds): Aphids as Crop Pests, pp 261-286 (CABI, Wallingford 2007).

Funabiki H, Hagan I, Uzawa S, Yanagida M: Cell cycle-dependent specific positioning and clustering of centromeres and telomeres in fission yeast. J Cell Biol 121:961-976 (1993).

- Gasser S: Positions of potential: nuclear organization and gene expression. Cell 104:639-642 (2001).

-Gilson E, Laroche T, Gasser SM: Telomeres and the functional architecture of the nucleus. Trends Cell Biol 3:128-134 (1993).

Grund SE, Fischer T, Cabal GG, Antunez O, Perez-Ortin JE, Hurt E: The inner nuclear membrane protein $\mathrm{Srcl}$ associates with subtelomeric genes and alters their regulated gene expression. J Cell Biol 182:897-910 (2008).

-Guelen L, Pagie L, Brasset E, Meuleman W, Faza $\mathrm{MB}$, et al: Domain organization of human chromosomes revealed by mapping of nuclear lamina interactions. Nature 453:948-951 (2008).

-Guerra M, García MA: Heterochromatin and rDNA sites distribution in the holocentric chromosomes of Cuscuta approximata Bab. (Convolvulaceae). Genome 47: 134-140 (2004).

Hughes-Schrader S, Schrader F: The kinetochore of the Hemiptera. Chromosoma 12:327-350 (1961).

Ikegami K, Egelhofer TA, Strome S, Lieb JD: Caenorhabditis elegans chromosome arms are anchored to the nuclear membrane via discontinuous association with LEM-2. Genome Biol 11:R120 (2010).

-Jin Q, Trelles-Stricken E, Scherthan H, Loidl J: Yeast nuclei display prominent centromere clustering that is reduced in non-dividing cells in meiotic prophase. J Cell Biol 141:2129 (1998).

-Lee KK, Gruenbaum Y, Spann P, Liu J, Wilson KL: C. elegans nuclear envelope proteins emerin, MAN1, lamin, and nucleoporins reveal unique timing of nuclear envelope breakdown during mitosis. Mol Biol Cell 11:30893099 (2000).
Leitch AR: Higher levels of organization in the interphase nucleus of cycling and differentiated cells. Microbiol Mol Biol Rev 64:138-152 (2000).

Loxdale HD: What's in a clone: the rapid evolution of aphid asexual lineages in relation to geography, host plant adaptation and resistance to pesticides, in Schon I, Martens K, van Dijk P (eds): Lost Sex: The Evolutionary Biology of Parthenogenesis, pp 535-557 (Springer, Heidelberg 2009).

Mandrioli M, Manicardi GC: Unlocking holocentric chromosomes: new perspectives from comparative and functional genomics? Curr Genom 13:343-349 (2012).

Mandrioli M, Bizzaro D, Manicardi GC, Gionghi D, Bassoli L, Bianchi U: Cytogenetic and molecular characterization of a highly repeated DNA sequence in the peach potato aphid Myzus persicae. Chromosoma 108:436-442 (1999a).

-Mandrioli M, Bizzaro D, Giusti M, Manicardi GC, Bianchi U: The role of rDNA genes in X chromosomes association in the aphid Acyrthosiphon pisum. Genome 42:381-386 (1999b).

-Mandrioli M, Azzoni P, Lombardo G, Manicardi GC: Composition and epigenetic markers of heterochromatin in the aphid Aphis nerii (Hemiptera: Aphididae). Cytogenet Genome Res 133:67-77 (2011).

Monti V, Mandrioli M, Rivi M, Manicardi GC: The vanishing clone: occurrence of repeated chromosome fragmentations in the aphid Myzus persicae (Homoptera, Aphididae). Biol J Linn Soc 105:350-358 (2012a).

Monti V, Lombardo G, Loxdale HD, Manicardi GC, Mandrioli M: Continuous occurrence of intra-individual chromosome rearrangements in the peach potato aphid, Myzus persicae (Sulzer) (Hemiptera: Aphididae). Genetica 140:93-103 (2012b).

-Monti V, Serafini C, Manicardi GC, Mandrioli M: Characterization of non-LTR retrotransposable TRAS elements in the aphids Acyrthosiphon pisum and Myzus persicae (Aphididae, Hemiptera). J Heredity 104:547-553 (2013).

-Ostashevsky JA: Polymer model for large-scale chromatin organization in lower eukaryotes. Mol Biol Cell 13:2157-2169 (2002).

-Peric-Hupkes D, Meuleman W, Pagie L, Bruggeman SW, Solovei I, et al: Molecular maps of the reorganization of genome-nuclear lamina interactions during differentiation. Mol Cell 38:603-613 (2010).

Pickersgill H, Kalverda B, de Wit E, Talhout W, Fornerod M, van Steensel B: Characterization of the Drosophila melanogaster genome at the nuclear lamina. Nat Genet 38:1005-1014 (2006).

Rabl C: Über Zellteilung. Morphol Jahrb 10:214330 (1885).
Rawlins DJ, Shaw PJ: 3-Dimensional organization of ribosomal DNA in interphase nuclei of Pisum sativum by in situ hybridization and optical tomography. Chromosoma 99:143151 (1990).

Reddy KL, Zullo JM, Bertolino E, Singh H: Transcriptional repression mediated by repositioning of genes to the nuclear lamina. Nature 452:243-247 (2008).

Santos AP, Abranches R, Stoger E, Beven A, Viegas $\mathrm{W}$, Shaw PJ: The architecture of interphase chromosomes and gene positioning are altered by changes in DNA methylation and histone acetylation. J Cell Sci 115:4597-4605 (2002).

-Schneider R, Grosschedl R: Dynamics and interplay of nuclear architecture, genome organization, and gene expression. Genes Dev 21: 3027-3043 (2007).

-Schubert I, Shaw P: Organization and dynamics of plant interphase chromosomes. Trends Plant Sci 16:273-281 (2011).

-Schweizer D, Loidl J: A model for heterochromatin dispersion and the evolution of C-band patterns. Chromosomes Today 9:61-74 (1987).

-Shaw PJ, Abranches R, Santos AP, Beven AF, Stoger E, Gonzalez-Melendia P: The architecture of interphase chromosomes and nucleolar transcription sites in plants. J Struct Biol 140: 31-38 (2003).

-Spector DL: The dynamics of chromosome organization and gene regulation. Ann Rev Biochem 72:573-608 (2003).

-Spence JM, Blackman RL, Testa JM, Ready PD: A 169 bp tandem repeat DNA marker for subtelomeric heterochromatin and chromosomal rearrangements in aphids of the Myzus persicae group. Chromosome Res 6:167-175 (1998).

Sperling K, Luedeke EK: Arrangement of prematurely condensed chromosomes in cultured cells and lymphocytes of the Indian muntjac. Chromosoma 83:541-553 (1981).

Ulbert S, Antonin W, Platani M, Mattaj IW: The inner nuclear membrane protein Lem 2 is critical for normal nuclear envelope morphology. FEBS Lett 580:6435-6441 (2006).

White MJ: Animal Cytology and Evolution, p 961 (Cambridge University Press, Cambridge 1973).

Wilson KL: The nuclear envelope, muscular dystrophy, and gene expression. Trends Cell Biol 10:125-129 (2000)

Wrensch DL, Kethley JB, Norton RA: Cytogenetics of holokinetic chromosomes and inverted meiosis: keys to the evolutionary success of mites, with generalization on eukaryotes, in Houck MA (ed): Mites: Ecological and Evolutionary Analyses of Life-History Patterns, pp 282-343 (Chapman \& Hall, New York 1994).

Zwick MS, Hanson RE, McKnight TD, Nurul-Islam-Faridi M, Stelly DM: A rapid procedure for the isolation of $\mathrm{C}_{0} \mathrm{t}-1 \mathrm{DNA}$ from plants. Genome 40:138-142 (1997). 